\title{
Gene duplications are extensive and contribute significantly to the toxic proteome of nematocysts isolated from Acropora digitifera (Cnidaria: Anthozoa: Scleractinia)
}

Ranko Gacesa', Ray Chung ${ }^{2}$, Simon R. Dunn ${ }^{3}$, Andrew J. Weston ${ }^{4}$, Adrian Jaimes-Becerra ${ }^{5}$, Antonio C. Marques ${ }^{5,6}$, André C. Morandini ${ }^{5}$, Daslav Hranueli ${ }^{7}$, Antonio Starcevic ${ }^{7}$, Malcolm Ward ${ }^{2}$ and Paul F. Long ${ }^{1,8,9,10^{*}}$

\begin{abstract}
Background: Gene duplication followed by adaptive selection is a well-accepted process leading to toxin diversification in venoms. However, emergent genomic, transcriptomic and proteomic evidence now challenges this role to be at best equivocal to other processess. Cnidaria are arguably the most ancient phylum of the extant metazoa that are venomous and such provide a definitive ancestral anchor to examine the evolution of this trait.

Methods: Here we compare predicted toxins from the translated genome of the coral Acropora digitifera to putative toxins revealed by proteomic analysis of soluble proteins discharged from nematocysts, to determine the extent to which gene duplications contribute to venom innovation in this reef-building coral species. A new bioinformatics tool called HHCompare was developed to detect potential gene duplications in the genomic data, which is made freely available (https://github.com/rgacesa/HHCompare).

Results: A total of 55 potential toxin encoding genes could be predicted from the A. digitifera genome, of which 36 (65\%) had likely arisen by gene duplication as evinced using the HHCompare tool and verified using two standard phylogeny methods. Surprisingly, only $22 \%(12 / 55)$ of the potential toxin repertoire could be detected following rigorous proteomic analysis, for which only half $(6 / 12)$ of the toxin proteome could be accounted for as peptides encoded by the gene duplicates. Biological activities of these toxins are dominatedby putative phospholipases and toxic peptidases.
\end{abstract}

Conclusions: Gene expansions in A. digitifera venom are the most extensive yet described in any venomous animal, and gene duplication plays a significant role leading to toxin diversification in this coral species. Since such low numbers of toxins were detected in the proteome, it is unlikely that the venom is evolving rapidly by preydriven positive natural selection. Rather we contend that the venom has a defensive role deterring predation or harm from interspecific competition and overgrowth by fouling organisms. Factors influencing translation of toxin encoding genes perhaps warrants more profound experimental consideration.

Keywords: Coral, Nematocyst, Venom, Proteome, Evolution, Hidden Markov model (HMM)

\footnotetext{
* Correspondence: paul.long@kcl.ac.uk

${ }^{1}$ Institute of Pharmaceutical Science, King's College London, 150 Stamford

Street, London SE1 9NH, UK

${ }^{8}$ Department of Chemistry, King's College London, Strand, London WC2R

2LS, UK

Full list of author information is available at the end of the article
}

\section{Biomed Central}

(c) 2015 Gacesa et al. Open Access This article is distributed under the terms of the Creative Commons Attribution 4.0 International License (http://creativecommons.org/licenses/by/4.0/), which permits unrestricted use, distribution, and reproduction in any medium, provided you give appropriate credit to the original author(s) and the source, provide a link to the Creative Commons license, and indicate if changes were made. The Creative Commons Public Domain Dedication waiver (http://creativecommons.org/publicdomain/zero/1.0/) applies to the data made available in this article, unless otherwise stated. 


\section{Background}

Venoms are usually complex mixtures of peptides and proteins colloquially known as toxins. These toxins can disrupt cellular functions or physiological processes, but venoms differ from poisons in that the venom must be delivered through specialised anatomical structures, such as fangs or stinging devices, that inflict a wound to the target prey or predator. This generally accepted definition includes also that toxins are biosynthesised and the venom is then secreted from specialised glands [1]. However, this definition falls short for a group of venomous invertebrates called the cnidarians that do not have any glandular tissues for toxin secretion. Instead, venom is produced by the Golgi apparatus of specialised cells called cnidocysts that are organised for toxin delivery by discharge of a secretory organelle called the cnida, which is unique to cnidarians and a defining characteristic of this phylum $[2,3]$.

Cnidaria has two major linages; the Anthozoa (sea anemones and corals) and Medusozoa, comprising the classes Staurozoa (stalked jellyfish), Cubozoa (box jellyfish), Scyphozoa ('true' jellyfish) and Hydrozoa (Hydra and relatives including several species of small jellyfish); see [2, 4] for a recent review. Human envenomation by cnidarians is common and, although seldom life-threatening, fatal contact with certain jellyfish such as the cubozoan Chironex fleckeri (the Australian Sea Wasp) is well documented in both the scientific literature and lay press [5]. There have been numerous studies characterising the venoms of many animals, but until recently the toxin component and function of cnidarian venoms was poorly studied and near completely unknown [6]. Still now, patterns for cnidarian venoms are variable and uncertain. We have previously used a high throughput proteomics approach to characterise putative toxins from the nematocysts (a type of cnida) of the coral Stylophora pistillata [7] and the hydrozoan jellyfish Olindias sambaquiensis [8]. The biological diversity and sequence similarity between these cnidarian toxins and those of completely unrelated higher animals were astounding, suggesting that at least some universal molecular processes leading to toxin diversification might be shared between basal metazoans and diverging lineages of venomous animals.

It is conventionally accepted that venom systems arose by a 'birth and death' process following convergent recruitment of ancestral genes that originally encoded non-toxic physiological functions [9]. These genes underwent duplication followed by rapid hyper-mutation independently in different animals to evolve proteins with cytotoxic functions when expressed in venom gland tissues $[10,11]$. Adaptive selection has retained useful paralog genes, which in turn has given rise to larger toxin-specific gene families, for example: phospholipase A2, serine proteases, C-type lectins and coagulation factor $\mathrm{V}$, which are regularly present in many venomous animals [12-16]. Venoms diversified additionally as more species-restricted gene families, such as the snake three-finger toxins [17], scorpion cysteine-enriched toxins [18] and the conotoxins of marine cone snails [19], evolved This 'birth and death' hypothesis has been refined recently, based upon genome sequence data analysis of predicted proteins from the non-venomous Burmese python Python molurus bivittatus [20]. Using tissue specific gene expression profiling, evidence provides that some genes encoding physiological functions are orthologs of toxin encoding genes which are differentially expressed in many different tissue types of the python. Specific recruitment of such orthologs into venom gland tissue followed by 'birth and death' evolution would result in paralogs where one copy would ultimately encode a toxic function. This explanation might, therefore, account for the large gene expansions seen in venom gland transcripts of xenophidian snakes [21], as well as that observed in the genome sequence of the highly venomous King Cobra Ophiophagus hannah [22]. Reverse recruitment of toxin encoding genes into non-venom gland tissue with reverse conversion of the gene products returning to a non-toxic physiological role has also been predicted from phylogenetic analyses [23] as demonstrated by comparative transcriptome analysis of toxin gene paralogs in venom gland and other tissues of the venomous snake Bothrops jararaca (South American pit viper) [24].

Comparative transcriptomics of venomous and nonvenomous reptiles however, has cast doubt on the extent to which recruitment and reverse recruitment processes play in the evolution of venom systems [25]. The 'restriction hypothesis' confirms previous findings that toxin orthologs are expressed in many tissues of nonvenomous reptiles, including salivary glands, suggesting that toxin orthologs have not been recruited but had already existed in glandular tissues [22-24]. Following gene duplication, paralogs can evolve so that expression of one copy, now encoding a toxic function, is restricted to the venom gland, whilst the original copy encoding a non-toxic physiological role remains expressed in other tissues [25]. The extent to which gene duplication has impacted on venom innovation has also been challenged because, although gene duplication in cone snail [26] and snake toxins [27] may occur at an enhanced rate, gene duplication in eukaryotes is generally considered a rare event [28]. In addition, evaluation of transcriptomic dataand sequence analysis of the duck-billed platypus (Ornithorhynchus anatinus) genome affirms that gene duplication did not contribute significantly to toxin diversification in this venomous mammal [29].

Other molecular processes that could lead to toxin diversification in lieu of gene duplications have been proposed. For example, although experimentally not proven, exon shuffling of primary mRNA transcripts has been 
suggested as a mechanism to account for active site variation in amino acid sequences of venom gland serine proteases in the snake Macrovipera schweizeri (Milos viper) [30]. Likewise, homologous recombination at the DNA or RNA levels may account also for sequence variation in Class P-I and P-II snake venom metalloproteinases (SVMP) in Bothrops neuwiedi (Neuweid's lancehead pit viper) [31]. However, such arguments have been based on mapping to sequences outside of known exon splicing sites in cDNA encoding a different SVMP class, which were obtained from the venom transcript of a taxonomically distant snake [32]. Hence, the extent to which toxin diversification can be attributed to processes of gene recruitment and duplication, or indeed recombination and alternative splicing of DNA or RNA, remain largely unexplored. This is principally due to a lack of sequenced genomes of venomous animals from which either true gene duplicates can be identified, or onto which RNA and peptide sequences can be mapped. In direct contrast, post-translational processes including amino acid modifications and protein splicing have been unequivocally established to increase conotoxin diversity in marine cone snail venoms [33].

The sequenced genomes of three cnidarians are currently available; these are Nematostella vectensis [34], Hydra magnipapillata [35] and Acropora digitifera [36]. There are numerous transcriptome libraries also for many cnidarians and, in addition to the nematocyst proteomes we have published $[7,8]$, the proteome of $H$. magnipapillata has likewise been reported that includes a description of putative toxins [37]. We have made freely available annotation of the predicted proteome of $A$. digitifera at ZoophyteBase (http://bioserv7.bioinfo.pbf.hr/Zoophyte/registration/ login.jsp). A search of this database revealed that the predicted toxins of $A$. digitifera are highly homologous to those toxins of many taxonomically distant venomous animals [38]. Having existed since at least the Pre-Cambrian era, Cnidaria are possibly the oldest lineage of extant animals to have evolved means to inject toxins into their prey $[4,39]$. If one assumes a single early evolutionary origin of toxin genes, Cnidaria thus provide a unique ancestral anchor to explore the genesis of toxin innovation, which have evolved independently to radiate in other venomous animals [40]. To assess the extent to which gene duplication drives toxin diversification in the Cnidaria, we herein compare the amino acid sequences of predicted toxins derived from the translated genome of $A$. digitifera to that of putative toxins observed by proteomic analysis of soluble proteins discharged from isolated nematocysts.

\section{Results}

Identification of potential toxin encoding genes in the $A$. digitifera genome

The translated genome of $A$. digitifera was searched for homology to known animal toxins in the UniProtKB/
Swiss-Prot Tox-Prot dataset. The BLAST search used an e-value cut-off selection criterion of $1.0 \mathrm{e}^{-5}$ that recovered 950 potential animal toxin homologs. To discriminate potential coral specific toxins from coral proteins with non-toxic physiological functions, these 950 hits were further filtered using an iterative five step process adapted from previously published methods for cnidarian toxin identification [41, 42]. Firstly, only sequences with Reciprocal Blast Best Hit (RBBH) or relaxed RBBH (using the top five BLAST hits for reciprocal BLAST) to sequences in the UniProtKB/Swiss-Prot Tox-Prot dataset with query coverage above $70 \%$ were retained. Secondly, BLASTp comparisons were performed against the entire UniProt database supplemented with additional cnidarian protein sequences [43] and, against a customised database constructed using only cnidarian protein sequences contained within UniProt. Only RBBH or relaxed RBBHs hits were retained having a cut-off e-value of less than $1.0 \mathrm{e}^{-5}$ for sequences from both databases . Thirdly, sequences were then manually validated for consistency, and all sequences giving higher scores to non-toxin protein family hits in the cnidarian supplemented UniProt database were discarded. Fourthly, sequences with two or more potential transmembrane domains, or having domain architectures different from known toxins, and Gene Ontology (GO) term assignments unlikely to be related to toxins were also excluded from further examination. Finally, the retained sequences were compared by BLASTp to the translated $A$. digitifera genome, and those with peptide sequences coverage greater than $75 \%$ and e-value homology below $1.0 \mathrm{e}^{-20}$ were predicted to be bona fide coral specific toxins. A total of 55 potential toxins could be recovered following this five stage filtering process. These 55 potential toxins are shown in Table 1, together with a expectation of likely biological function by inference to a known animal toxin with closest peptide sequence homology. Nearly a quarter (13/55) of the potential A. digitifera toxins shared most similar sequence homology to that of other known cnidarians toxins.

\section{Identification of potential gene duplicates}

Evaluation of the role that gene duplication plays in the evolution of toxin diversity requires phylogenetic analysis of sequence data to identify related paralogs from many closely related species. No such data exists for coral species; hence, potential gene duplicates were used as the most likely sequences to be best related to true paralogs. Gene duplicates were identified using a newly developed HMM-HMM based hierarchical clustering tool called HHCompare. Clustering was also performed using standard Maximum Likelihood and Maximum Parsimony phylogenetic methods. All three methods grouped together all of sequences related by identical 
Table 1 Predicted venom proteome of potential toxins from the translated genome sequence of Acropora digitifera

\begin{tabular}{|c|c|c|c|c|c|}
\hline $\begin{array}{l}\text { A. digitifera protein } \\
\text { accession number }\end{array}$ & $\begin{array}{l}\text { Predicted biological } \\
\text { effect }\end{array}$ & $\begin{array}{l}\text { Sequence homology } \\
\text { (e-value) }\end{array}$ & $\begin{array}{l}\text { Uniprot accession } \\
\text { number }\end{array}$ & Toxin with closest homology & $\begin{array}{l}\text { Example of animal species } \\
\text { with closest homology }\end{array}$ \\
\hline adi_v1.16452 & Cytolysin & $5.00 \mathrm{E}-55$ & J3SBP3 & Phosphodiesterase & $\begin{array}{l}\text { Crotalus adamanteus (Eastern } \\
\text { diamondback rattlesnake) }\end{array}$ \\
\hline adi_v1.02125 & Cytolysin & $2.0 \mathrm{E}-137$ & J3SBP3 & Phosphodiesterase & $\begin{array}{l}\text { Crotalus adamanteus (Eastern } \\
\text { diamondback rattlesnake) }\end{array}$ \\
\hline adi_v1.08969 & Cytolysin & $1.0 \mathrm{E}-76$ & F8J2D3 & Phospholipase-B & $\begin{array}{l}\text { Drysdalia coronoides } \\
\text { (White-lipped snake) }\end{array}$ \\
\hline adi_v1.12172 & Cytolysin & 4.0E-121 & F8J2D3 & Phospholipase-B & $\begin{array}{l}\text { Drysdalia coronoides } \\
\text { (White-lipped snake) }\end{array}$ \\
\hline adi_v1.14353 & Cytolysin & $2.0 \mathrm{E}-83$ & [43] & $\Delta$-ALTX-Pse & $\begin{array}{l}\text { Phyllodiscus semoni (Night } \\
\text { sea anemone) }\end{array}$ \\
\hline adi_v1.09427 & Cytolysin & 7.0E-93 & {$[43]$} & $\Delta$-TATX-Avl2a & $\begin{array}{l}\text { Actineria villosa (Okinawan } \\
\text { sea anemone) }\end{array}$ \\
\hline adi_v1.16619 & Cytolysin & $3.00 \mathrm{E}-88$ & {$[43]$} & $\Delta$-TATX-Avl2a & $\begin{array}{l}\text { Actineria villosa (Okinawan } \\
\text { sea anemone) }\end{array}$ \\
\hline adi_v1.16440 & Cytolysin & $1.00 \mathrm{E}-12$ & [43] & $\Delta$-AITX-Aas1a (Bandaporin) & $\begin{array}{l}\text { Anthopleura asiatica (Giant } \\
\text { green sea anemone) }\end{array}$ \\
\hline adi_v1.24162 & Cytolysin & $3.00 \mathrm{E}-11$ & P61914 & Equinatoxin-2 (Actinoporin) & $\begin{array}{l}\text { Actinia equina (Beadlet } \\
\text { sea anemone) }\end{array}$ \\
\hline adi_v1.04835 & Cytolysin & $2.0 \mathrm{E}-120$ & J3SDX8 & Lipase & $\begin{array}{l}\text { Crotalus adamanteus (Eastern } \\
\text { diamondback rattlesnake) }\end{array}$ \\
\hline adi_v1.23821 & Cytolysin & $3.00 \mathrm{E}-101$ & J3SDX8 & Lipase & $\begin{array}{l}\text { Crotalus adamanteus (Eastern } \\
\text { diamondback rattlesnake) }\end{array}$ \\
\hline adi_v1.01810 & Cytolysin & $7.0 \mathrm{E}-65$ & J3SDX8 & Lipase & $\begin{array}{l}\text { Crotalus adamanteus (Eastern } \\
\text { diamondback rattlesnake) }\end{array}$ \\
\hline adi_v1.09322 & Cytolysin & $4.0 \mathrm{E}-47$ & J3RZ81 & Lipase & $\begin{array}{l}\text { Crotalus adamanteus (Eastern } \\
\text { diamondback rattlesnake) }\end{array}$ \\
\hline adi_v1.00020 & Cytolysin & $1.0 \mathrm{E}-39$ & J3RZ81 & Lipase & $\begin{array}{l}\text { Crotalus adamanteus (Eastern } \\
\text { diamondback rattlesnake) }\end{array}$ \\
\hline adi_v1.12434 & Cytolysin & $1.00 \mathrm{E}-43$ & $\mathrm{~A} 2 \mathrm{VBC} 4$ & Phospholipase A1 & $\begin{array}{l}\text { Polybia paulista (Neotropical } \\
\text { social wasp) }\end{array}$ \\
\hline adi_v1.09601 & Cytolysin & $2.0 \mathrm{E}-16$ & Q93109 & Equinatoxin-5 (Actinoporin) & $\begin{array}{l}\text { Actinia equina (Beadlet } \\
\text { sea anemone) }\end{array}$ \\
\hline adi_v1.10410 & Cytolysin & 4.0E-52 & Reference [43] & $\Delta$-AITX-Ucs1a (Urticinatoxin) & $\begin{array}{l}\text { Urticina crassicornis (Christmas } \\
\text { sea anemone) }\end{array}$ \\
\hline adi_v1.12125 & Cytolysin & $2.00 \mathrm{E}-26$ & J3S836 & Phosphodiesterase & $\begin{array}{l}\text { Crotalus adamanteus (Eastern } \\
\text { diamondback rattlesnake) }\end{array}$ \\
\hline adi_v1.06821 & Cytolysin & $2.0 \mathrm{E}-78$ & A3QVN9 & Hyaluronidase & $\begin{array}{l}\text { Bitis arietans (African puff } \\
\text { adder) }\end{array}$ \\
\hline adi_v1.16469 & Cytolysin & $5.00 \mathrm{E}-13$ & P81383 & L-amino-acid oxidase & $\begin{array}{l}\text { Ophiophagus hannah } \\
\text { (King cobra) }\end{array}$ \\
\hline adi_v1.12311 & Cytolysin & $2.0 \mathrm{E}-16$ & A7L035 & Toxin CfTX-1 & Chironex fleckeri (Box jellyfish) \\
\hline adi_v1.16921 & Disrupts haemostasis & $3.00 \mathrm{E}-28$ & $\mathrm{D} 2 \times 8 \mathrm{~K} 2$ & Phospholipase A2 & $\begin{array}{l}\text { Condylactis gigantea (Giant } \\
\text { Caribbean sea anemone) }\end{array}$ \\
\hline adi_v1.16374 & Disrupts haemostasis & $8.0 \mathrm{E}-32$ & Q58L94 & $\begin{array}{l}\text { Prothrombin activator } \\
\text { (Notecarin) }\end{array}$ & $\begin{array}{l}\text { Notechis scutatus scutatus } \\
\text { (Tiger snake) }\end{array}$ \\
\hline adi_v1.15821 & Disrupts haemostasis & $5.0 \mathrm{E}-41$ & Q4QXT9 & Coagulation factor $X$ & $\begin{array}{l}\text { Tropidechis carinatus (Rough } \\
\text { scaled snake) }\end{array}$ \\
\hline adi_v1.08904 & Disrupts haemostasis & $5.0 \mathrm{E}-35$ & Q76B45 & $\begin{array}{l}\text { Serine-type endopeptidase } \\
\text { (Blarina toxin) }\end{array}$ & $\begin{array}{l}\text { Blarina brevicauda (Northern } \\
\text { short-tailed shrew) }\end{array}$ \\
\hline adi_v1.19445 & Disrupts haemostasis & 8.0E-112 & C6JUN2 & Metalloprotease (SVMP) & $\begin{array}{l}\text { Philodryas olfersii (Green } \\
\text { snake) }\end{array}$ \\
\hline adi_v1.14946 & Disrupts haemostasis & $1.0 \mathrm{E}-30$ & B6EWW8 & Snake venom 5'-nucleotidase & $\begin{array}{l}\text { Gloydius brevicaudus (Korean } \\
\text { slamosa snake) }\end{array}$ \\
\hline
\end{tabular}


Table 1 Predicted venom proteome of potential toxins from the translated genome sequence of Acropora digitifera (Continued)

\begin{tabular}{|c|c|c|c|c|c|}
\hline adi_v1.12298 & Disrupts haemostasis & 4.0E-15 & Q4PRC6 & Snaclec 7 & $\begin{array}{l}\text { Daboia siamensis (Eastern } \\
\text { Russel's viper) }\end{array}$ \\
\hline adi_v1.18989 & Disrupts haemostasis & $6.00 \mathrm{E}-08$ & Q66S13 & Fish venom Natterin-4 & $\begin{array}{l}\text { Thalassophryne nattereri } \\
\text { (Niquim) }\end{array}$ \\
\hline adi_v1.19802 & Disrupts haemostasis & $1.0 \mathrm{E}-19$ & A7X3Z0 & C-type lectin (Lectoxin-Thr1) & $\begin{array}{l}\text { Thrasops jacksonii (Jackson's } \\
\text { black tree snake) }\end{array}$ \\
\hline adi_v1.06850 & Disrupts haemostasis & $9.0 \mathrm{E}-16$ & A8QZJ5 & Cytotoxin-1 & $\begin{array}{l}\text { Millepora dichotoma } \\
\text { (Net fire coral) }\end{array}$ \\
\hline adi_v1.22096 & Disrupts haemostasis & $2.00 \mathrm{E}-68$ & D8VNT0 & Ryncolin-4 & $\begin{array}{l}\text { Cerberus rynchops (Dog-faced } \\
\text { water snake) }\end{array}$ \\
\hline adi_v1.19322 & $\begin{array}{l}\text { Induces immune } \\
\text { response }\end{array}$ & 4.0E-19 & P35779 & Venom allergen 3 & $\begin{array}{l}\text { Solenopsis richteri (Black } \\
\text { imported fire ant) }\end{array}$ \\
\hline adi_v1.01092 & $\begin{array}{l}\text { Induces immune } \\
\text { response }\end{array}$ & $5.0 \mathrm{E}-36$ & J3SFJ3 & $\begin{array}{l}\text { Translationally-controlled } \\
\text { tumor protein homolog }\end{array}$ & $\begin{array}{l}\text { Crotalus adamanteus (Eastern } \\
\text { diamondback rattlesnake) }\end{array}$ \\
\hline adi_v1.11797 & Neurotoxin & $3.0 \mathrm{E}-30$ & P00615 & Phospholipase A2 & $\begin{array}{l}\text { Oxyuranus scutellatus scutellatus } \\
\text { (Australian taipan) }\end{array}$ \\
\hline adi_v1.18628 & Neurotoxin & $8.0 \mathrm{E}-15$ & Q9TWL9 & Phospholipase A2 (Conodipine-M) & $\begin{array}{l}\text { Conus magus (Magician's } \\
\text { cone snail) }\end{array}$ \\
\hline adi_v1.05505 & Peptidase & $1.0 \mathrm{E}-41$ & C9WMM5 & Serine carboxypeptidase & Apis mellifera (Honeybee) \\
\hline adi_v1.05180 & Peptidase & $7.0 \mathrm{E}-52$ & B2D0J5 & Serine carboxypeptidase & Apis mellifera (Honeybee) \\
\hline adi_v1.11218 & Proteinase inhibitor & $3.0 \mathrm{E}-17$ & Q6ITB9 & $\begin{array}{l}\text { Kunitz-type serine protease } \\
\text { inhibitor (Mulgin-3) }\end{array}$ & $\begin{array}{l}\text { Pseudechis australis (King } \\
\text { brown snake) }\end{array}$ \\
\hline adi_v1.23374 & Proteinase inhibitor & $8.0 \mathrm{E}-17$ & P0C8W3 & $\begin{array}{l}\text { Kunitz-type serine protease } \\
\text { inhibitor }(\mathrm{Hg} 1)\end{array}$ & $\begin{array}{l}\text { Hadrurus gertschi (Desert } \\
\text { hairy scorpion) }\end{array}$ \\
\hline adi_v1.09855 & Unknown & $3.0 \mathrm{E}-136$ & B2DCR8 & SE-cephalotoxin & $\begin{array}{l}\text { Sepia esculenta (Golden } \\
\text { cuttlefish) }\end{array}$ \\
\hline adi_v1.20368 & Venom maturation & $2.0 \mathrm{E}-51$ & K7Z9Q9 & $\begin{array}{l}\text { Metalloprotease (Nematocyte } \\
\text { expressed protein 6) }\end{array}$ & $\begin{array}{l}\text { Nematostella vectensis } \\
\text { (Starlet sea anemone) }\end{array}$ \\
\hline adi_v1.17845 & Venom maturation & $3.0 \mathrm{E}-44$ & K7Z9Q9 & $\begin{array}{l}\text { Metalloprotease (Nematocyte } \\
\text { expressed protein 6) }\end{array}$ & $\begin{array}{l}\text { Nematostella vectensis } \\
\text { (Starlet sea anemone) }\end{array}$ \\
\hline adi_v1.13648 & Venom maturation & 4.0E-38 & K7Z9Q9 & $\begin{array}{l}\text { Metalloprotease (Nematocyte } \\
\text { expressed protein 6) }\end{array}$ & $\begin{array}{l}\text { Nematostella vectensis } \\
\text { (Starlet sea anemone) }\end{array}$ \\
\hline adi_v1.07444 & Venom maturation & $1.0 \mathrm{E}-28$ & C9D7R3 & Metalloprotease (Astacin-like toxin) & $\begin{array}{l}\text { Loxosceles intermedia } \\
\text { (Brown spider) }\end{array}$ \\
\hline adi_v1.23604 & Venom maturation & $3.0 \mathrm{E}-21$ & C9D7R2 & Metalloprotease (Astacin-like toxin) & $\begin{array}{l}\text { Loxosceles intermedia } \\
\text { (Brown spider) }\end{array}$ \\
\hline adi_v1.15751 & Venom maturation & 7.00E-37 & AOFKN6 & Metalloprotease (Astacin-like toxin) & $\begin{array}{l}\text { Loxosceles intermedia } \\
\text { (Brown spider) }\end{array}$ \\
\hline adi_v1.20292 & Venom maturation & $5.0 \mathrm{E}-28$ & B1A4F7 & Venom dipeptidyl peptidase 4 & $\begin{array}{l}\text { Vespula vulgaris (Yellow } \\
\text { jacket wasp) }\end{array}$ \\
\hline adi_v1.15074 & Venom maturation & 2.0E-28 & B1A4F7 & Venom dipeptidyl peptidase 4 & $\begin{array}{l}\text { Vespula vulgaris (Yellow } \\
\text { jacket wasp) }\end{array}$ \\
\hline adi_v1.09733 & Venom maturation & $9.0 \mathrm{E}-29$ & Q9TXD8 & Serine type endopeptidase & $\begin{array}{l}\text { Agelenopsis aperta (North } \\
\text { American funnel-web spider) }\end{array}$ \\
\hline adi_v1.03437 & Venom maturation & $6.0 \mathrm{E}-13$ & Q3SB11 & Calglandulin & $\begin{array}{l}\text { Tropidechis carinatus (Australian } \\
\text { rough-scaled snake) }\end{array}$ \\
\hline adi_v1.01102 & Venom maturation & $5.0 \mathrm{E}-38$ & Q3SB11 & Calglandulin & $\begin{array}{l}\text { Tropidechis carinatus (Australian } \\
\text { rough-scaled snake) }\end{array}$ \\
\hline adi_v1.05162 & Venom maturation & $1.0 \mathrm{E}-47$ & J3S9D9 & $\begin{array}{l}\text { Phospholipase A2 activation } \\
\text { (Reticulocalbin-2) }\end{array}$ & $\begin{array}{l}\text { Crotalus adamanteus (Eastern } \\
\text { diamondback rattlesnake) }\end{array}$ \\
\hline adi_v1.10508 & Venom maturation & $5.0 \mathrm{E}-53$ & Q8MMH3 & $\begin{array}{l}\text { Protein-glutamate } \\
\text { O-methyltransferase }\end{array}$ & $\begin{array}{l}\text { Pimpla hypochondriaca } \\
\text { (Parasitoid wasp) }\end{array}$ \\
\hline
\end{tabular}


function (Fig. 1), although there was a slight difference in the number of groups generated by the different methods (Additional file 1). Tajima's test of neutrality was performed on each group containing more than 2 domain sequences and, in all cases produced a D statistic greater or equal to 4 , indicating balancing selection. When taking the results from the three clustering methods together (Fig. 1), the positioning of 36/55 (65\%) sequences within specific groups inferred that these sequences had arisen following gene duplication events. These 36 sequences could be divided amongst 13 groups with predominantly cytotoxic or toxic protease activities. The remaining 19 sequences could not be grouped and were regarded as singlets, again with mainly cytotoxic activities, possibly involved in affecting haemostasis, immune function, neurotoxicity or toxin maturation.

\section{Identification of potential toxins in the proteome of $A$. digitifera nematocysts}

Mass spectral data of peptide fragments obtained from tryptic digests of soluble proteins extracted from discharged nematocysts were first matched for identity to the predicted toxins of $A$. digitifera (Table 1). Stringent identity criteria of two peptide matches at greater than $95 \%$ sequence similarity were selected that gave just 12 homologous matches, representing $22 \%(12 / 55)$ of the potential toxins in the translated genome sequence. A MASCOT search (i.e., two peptide matches with $>95 \%$ sequence similarity) of the spectral data for matches to the predicted proteome of Symbiodinium clade B1 was performed to also identify any endosymbiotic algal peptide sequences with homology to predicted A. digitifera toxins. No potential contaminating Symbiodinium clade B1 proteins were identified despite using a BLAST search with a stringent e-value cut off selection criterion of $1.0 \mathrm{e}^{-20}$. The venom toxins of $A$. digitifera had a relatively narrow profile of predicted biological activities such to include phospholipases and pore forming toxins, toxic peptides and peptides predicted to disrupt haemostasis or immune function. Metalloproteases and other peptidases possibly involved in venom toxin maturation were also annotated as part of the expected toxin proteome. Of the 36 peptides attributed to gene duplication, 6 were detected in the proteome which represented $50 \%$ $(6 / 12)$ of the total peptides in the expressed venom. Manual validation of mass spectra for annotation of 19 potentially unique $A$. digitifera coral toxins was assessed by searching the PRIDE proteomics data repository (http:// www.ebi.ac.uk/pride/archive/) for the dataset named 'Acropora_Digitifera_Toxins', with sequences in FASTA format are also available from ZoophyteBase (http://bioserv7.bioinfo.pbf.hr/Zoophyte/registration/login.jsp [38]).

\section{Discussion}

Toxin diversification in venoms is traditionally accepted to have arisen by convergent recruitment of genes that have evolved independently within the glandular tissues of diverse animal lineages, following common molecular processes of DNA sequence duplication and deletion [1, 9-11, 20, 24, 25]. Yet, the concept that gene recruitment, sequence duplication and sequence deletion alone are sufficient to explain the surprising chemical diversity of toxins in venoms is increasingly being challenged as genome, transcriptome and proteome data from venomous animals are becoming available [29, 33, 44]. Cnidaria is likely to be the most basal of extant metazoans to be venomous, so we used Acropora digitifera for which we had already annotated the predicted proteome [38] to evaluate the extent to which gene duplication could account for toxin diversification in this reef-building coral.

Here, a BLAST homology search of the A. digitifera predicted proteome against the UniProtKB/Swiss-Prot Tox-Prot dataset, followed by a stringent five step process to exclude proteins with possible non-toxic physiological functions [41-43], uncovered 55 potential toxins with homology to higher animal toxins (Table 1). This was a low number of potential toxin encoding genes in comparison to that of the two venomous vertebrates for which genome sequences are presently available. Such, there were 107 potential toxin encoding genes identified by similarity to known toxins encoded in the genome of the Duck-billed platypus Ornithorhynchus anatinus [29], and 69 predicted toxin encoding genes with homology to toxin families were identified in the genome sequence of the King cobra Ophiophagus hannah [22]. However, there was a disparity between the higher numbers of predicted toxin encoding genes that had arisen from likely duplication events identified in this study (36/55, $65 \%$ ) as compared to much lower numbers of gene duplicates in the Duck-billed platypus and King cobra genomes. Of the 107 platypus genes with significant sequence similarity to known toxins, only 16 $(15 \%)$ were likely to have evolved subsequent to a duplication event; this low number would suggest that the venom of the platypus is diversifying slowly and likely under negative selection. Indeed, the 16 gene duplicates were not members of any major known lethal toxin gene families, and so the venom is unlikely to be under strong adaptive (i.e., positive) evolutionary pressure, thereby producing venom of low potency [29]. This would agree with the likely purpose attributed to platypus venom, which is to incapacitate rather than to kill mating competitors [44], a widespread common sexual selection pattern among mammals. In contrast, the 69 potential toxin encoding genes predicted in the genome of the King cobra have undergone massive expansion, with 30 (i.e., $43 \%$ ) likely to have arisen following gene duplication. Of these 30 duplicates, 25 were 
concentrated in just three major lethal toxin gene families, namely the three-finger toxins, phospholipase A2 and snake venom metalloproteinase enzymes [22]. This high number of gene duplications is consistent with natural selection for specific prey, which requires highly toxic and lethal venom that is evolving quickly to adapt to molecular co-evolution of prey resistance [45].

Evaluation of the role gene duplication plays in the evolution of toxin diversity in basal Metazoa requires bioinformatics methods to identify putative gene paralogs. There are currently two standard approaches based on either comparing the positions of paralogs on phylogenetic tree relationships or by assessing the degree of identity between sequences using BLAST similarity searching methods. Both methods require genomic, transcriptomic or proteomic data obtained from many closely related species in order to identify related paralogs. There are sequenced genomes only for three distantly related cnidarians available in the public domain, and so, tree and BLAST based approaches to identify paralogs is not dependable. Currently available clustering methods such as cd-hit and BLASTClust (ftp://ftp.ncbi.nih.gov/blast/documents/blastclust.html) from the NCBIBLAST package [46] can be used to infer potential orthology, but do not provide an evolutionary perspective, and such fall short in precision because they use BLAST-like algorithms. Comparison of similarity between groups of potential orthologs based on generating and then comparing hidden Markov models (HMMs) does allow inference of evolutionary distance. However, there are currently no tools available that compare HMMs and then cluster orthologous proteins to allow potential paralogs to be detected within ortholog clusters. For this reason we have developed a new tool called HHCompare. It implements well tested HHsuit programs for HMM generation and HMM vs HMM comparisons [47]. HHCompare then uses iterative pairwise HMM vs HMM comparisons to generate related ortholog groups based on high HMM-HMM similarity (e-value cut-off less than $1.0 \mathrm{e}^{-20}$ ) and then generates relationship trees to cluster the orthologous groups, thereby allowing potential orthologs in and between cluster groups to be detected. In this study, such a low e-value cut-off would only cluster extremely similar orthologous proteins, and so this approach was considered a proxy for likely gene duplication in the absence of sequences from closely related species. The strength of this clustering compared favourably against two standard methods of approach (Additional file 1). The 55 predicted toxins encoded in the $A$. digitifera genome formed 13 clusters with two or more sequences and 19 singlets (Fig. 1). This requires that an astounding $65 \%$ of the predicted venom of $A$. digitifera had likely arisen subsequent to gene duplication, which is far greater than the total expansion of toxin genes reported in the King cobra venom (43\% [22]). This degree of duplication is nearly equivalent to gene expansions reported for specific toxin families in other venomous animals. Conotoxin genes are thought to be the most rapidly evolving in the Metazoa with $70 \%$ of the Asuperfamily of conotoxin genes having been established by gene duplication [26]. In sharp contrast, genes encoding the sphingomyelinase D toxin in sicariid spiders are believed to be composed of only $4.4 \%$ of gene duplicates [48]. To our knowledge, $A$. digitifera has the greatest percentage of toxin encoding gene duplications yet reported in the genome of any venomous animal to date.

To assess what adaptive selective pressures might drive and maintain such massive gene expansions in $A$. digitifera, the expressed venom proteome was determined empirically using high throughput mass spectrometric protein analysis. When matched predicted toxins against the translated proteome sequence, and surprisingly only $22 \%(12 / 55)$ of the predicted proteome could be identified using strict spectral identification parameters. Although peptides likely to be products from gene duplicates accounted for $50 \%(6 / 12)$ of the toxic proteome, the high number of potential toxins not detected in the venom proteome might reflect poor promotor recognition and therefore weak expression of very recently duplicated genes such that protein abundance is less than the detection limits of the proteomics method [49]. Such a high number of gene duplicates would suggest that the venom is evolving rapidly under adaptive, positive selection. However, with so many of the gene duplicates not seemingly expressed in the empirically determined proteome would, in fact, indicate contrarily that the venom of A. digitifera has low toxicity since it is evolving gradually under negative selection. This is in broad agreement with data comparing multiple alignments of amino acid sequences and calculations of amino acid substitution rates, particularly for the sea anemone peptide neurotoxins and pore-forming toxins, which show these cnidarian toxins are under negative selection and thus are highly conserved [50]. Likewise, critical examination of the evolution of three species across cnidarian lineages (the anthozoan sea anemone Anemonia viridis (Actinaria), the scyphozoan jellyfish Aurelia aurita and the hydrozoan Hydra magnipapillata) agrees also with our data that venom of the anthozoan Acropora digitifera (Scleractinia) shows little evidence for diversification through positive selection [41].

The putative biological activities of the toxins in both the predicted and observed $A$. digitifera venom were dominated by cytotoxic phospholipases and pore forming toxins (Table 1 and Fig. 1). This is not unusual compared to the known or predicted pharmacological effects of toxins in other cnidarian venoms. For example, in anthozoans, of which sea anemone venoms are the most widely studied in all of the Cnidaria, their venoms are 


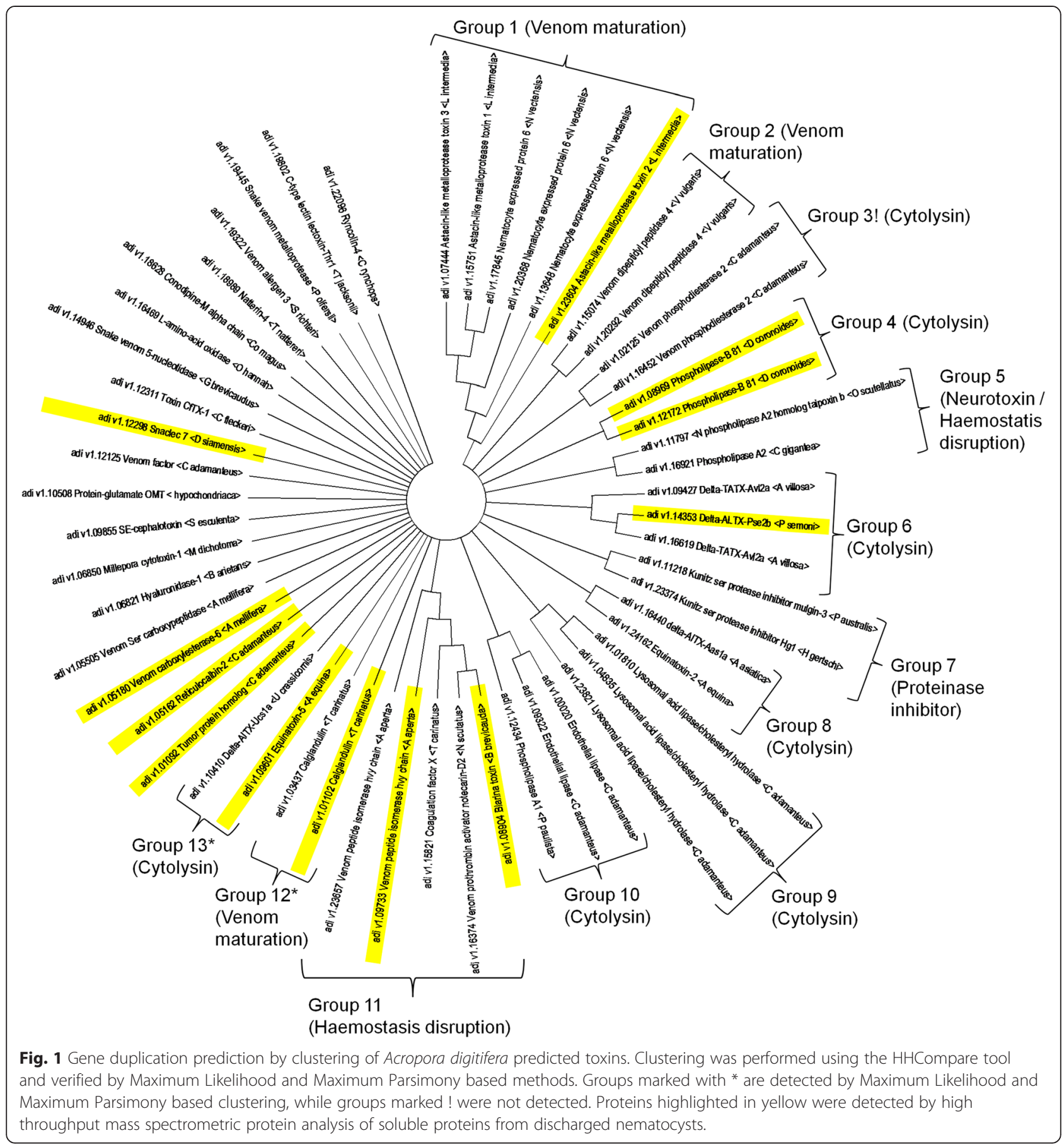

composed mainly of pore forming toxins and peptide neurotoxins [51]. Other anthozoan venoms are less widely studied, but our proteomic analysis of toxins from the coral Stylophora pistillata (Scleractinia) predicts that in this coral species venoms are also composed predominantly of cytotoxic peptides and neurotoxins [7]. The venoms of hydrozoans, such as those of the genus Millepora (commonly known as 'fire corals' and well known for human envenomation causing sever irritation) and Hydra, are composed mainly of cytolysins, phospholipase and haemolytic enzymes [52]. A. digitifera does feed on microscopic phytoplankton and zooplankton, however, like all of the reef-building corals, $A$. digitifera has evolved an endosymbiotic metabolic partnership with photosynthetic dinoflagellates of the genus Symbiodinium (Dinophyceae) which is essential for survival in the nutrient-poor waters of tropical marine environments $[53,54]$. The biological relevance of a largely 
cytolytic toxic arsenal could reflect a possible defensive role to deter fish predation and death by fouling organisms, including attack by coral-excavating sponges (Clionidae) which are strong competitors of corals for space on the reef shelf [55-57]. Biochemical studies to assign specific pore-forming activities to the $A$. digitifera cytolysins will require in future a comprehensive comparative review of pore-forming toxins in Cnidaria to better understand the provenance and biological relevance of these toxins to the life history strategy of these animals [58]. It is a wellaccepted concept that toxin gene acquisition follows duplication of genes encoding non-toxic physiological functions $[1,9]$. It follows that the toxin encoding genes that were considered as singlets in this study would have most likely have arisen following gene duplication that occurred in the very distant past such that strict evidence for duplication events could not be detected with the methods employed here. Developing an evolutionary clock to determine if the timing of gene duplication events and emergence of specific toxin gene families is correlated with a transition of cnidarians from sessile animals in photoautotrophic symbiosis to free living heterotrophic lineages is worthy of future research.

\section{Conclusions}

This is the first study to combine genome analysis and proteomics data to critically examine venom innovation in the Cnidaria and the relevance of gene duplication in toxin diversification in particular. After filtering proteins with likely non-toxic physiological function, 55 potentially unique coral toxins have been described. Exploring selection pressures and processes driving the evolution of venom is problematic in Cnidaria since few genomes of related species have been sequenced. Here we exemplify a new bioinformatics tool called HHCompare that overcomes the severity of this impediment. Using this tool, predicted toxin encoding genes of the coral $A$. digitifera could be divided into orthologous groups that are the closest representation to gene duplicates currently possible, which is consistent with groupings determined by conventional phylogenetic methods. Of the 55 toxins, 36 (65\%) are likely established by gene duplication, which represents the largest gene expansion as a percentage proportion of all toxin encoding genes identified in the genome in any venomous animal reported to date. Only $22 \%$ of these peptides were detected in the expressed proteome of discharged nematocysts, suggesting that the venom had evolved for predator defence rather than an offensive role for prey capture. Biochemical validation of toxin activities is now warranted so that full annotation of $A$. digitifera coral specific toxins can be deposited in publically available protein databases. Gene expansion by gene duplication appears crucial to toxin evolution in the basal Metazoa such as exemplified by the Cnidaria. Factors influencing translation of these gene products to enhance venom potency provides a fascinating avenue for further study.

\section{Methods}

\section{Isolation of nematocysts from coral}

Fragments of 3 colonies of the hermatypic coral A. digitifera were collected from reef flat sites adjacent to the Heron Island Research Station (S 23 $13^{\prime} 30^{\prime \prime}$, E $15^{\circ}$ 11'54”), Great Barrier Reef, Australia in November 2013 and were immediately snap frozen in $\mathrm{LN}_{2}$ for transport to the laboratory. The coral fragments were airbrushed on ice with $30 \mathrm{~mL}$ of $\mathrm{Ca}^{2+}$ free artificial seawater $(\mathrm{pH} 8.2 / 32 \mathrm{ppt})$ for tissue removal. The homogenised tissue slurry $(2 \mathrm{~mL})$ was placed on top of a dilution gradient density column consisting of $2 \mathrm{~mL}$ each of $30 \%$, $50 \%, 70 \%$ and $90 \%(\mathrm{w} / \mathrm{v})$ polyvinyl pyrrolidone (Percoll ${ }^{\circ}$ : Sigma) in artificial seawater and cooled on ice for $20 \mathrm{~min}$ prior to centrifugation at $4{ }^{\circ} \mathrm{C}$ for $10 \mathrm{~min}$ at $280 \times g$. Following centrifugation, the $50-70 \%$ layer that contained the highest concentration of undischarged nematocysts was collected and then freeze dried (MicroModulo-230 freeze drier in combination with a RVT100 refrigerated vapour trap, Thermo Savant). Corals were collected under permit G12/35434.1 issued by the Great Barrier Reef Marine Park Authority and coral material was transferred to the United Kingdom in accordance with CITES institutional permits AU053 and BG029.

\section{Proteomics}

To extract soluble proteins, $500 \mu \mathrm{L}$ of extraction buffer containing $50 \mathrm{mM}$ triethylammonium bicarbonate, $0.04 \%$ SDS (w/v), $1 \times$ Complete Mini Protease Inhibitors (Roche) and $1 \times$ Complete Mini Phosphatase Inhibitors reagent (Roche) was added to the freeze-dried coral material. The material was vortex for $1 \mathrm{~min}$ and then placed on ice for $1 \mathrm{~min}$; the procedure was repeated 10 times. The material was disrupted with a probe sonicator (model: VC250, Sonics \& Materials Inc.) whilst on ice for a total of $15 \mathrm{sec}$ using a duty cycle of $40 \%$ and an output of 3 . The material was centrifuged at $13,000 \times g$ for $15 \mathrm{~min}$ at $4{ }^{\circ} \mathrm{C}$. The protein concentration in the cleared supernatant was then measured by Nanodrop spectroscopy (Thermo Scientific) by averaging the results of three determinations. An extract portion containing $30 \mu \mathrm{g}$ of soluble protein in $2 \times$ Laemmli buffer (Sigma) was heated for $10 \mathrm{~min}$ at $90{ }^{\circ} \mathrm{C}$ and loaded onto a $4-12 \%(w / v)$ NuPAGE Novex Bis-Tris gel (Life Technologies) for separation by 1D SDS-PAGE electrophoresis using 2-( $N$-morpholino)-ethanesulfonic acid (MES) buffer alongside Novex SeeBlue Plus2 prestained molecular weight standards. Electrophoresis was carried out at $150 \mathrm{~V}$ for approximately $100 \mathrm{~min}$. The gel was fixed, Coomassie Blue-stained, de-stained and visualised by scanned image. The entire gel lane was sectioned into 15 equal portions and each section was divided into 
$2 \mathrm{~mm}^{2}$ portioned for in-gel digestion. Briefly, cysteine residues were reduced with $10 \mathrm{mM}$ dithiothrietol and alkylated with $55 \mathrm{mM}$ iodoacetamide in $100 \mathrm{mM}$ ammonium bicarbonate to form stable carbamidomethyl derivatives. Trypsin (Promega) solution was added to the gel sections at $13 \mathrm{ng} / \mu \mathrm{L}$ in $50 \mathrm{mM}$ ammonium bicarbonate and digestion was carried out at $37^{\circ} \mathrm{C}$ overnight. The supernatant was retained and the peptides were extracted from the gel sections by two washes with $50 \mathrm{mM}$ ammonium bicarbonate and acetonitrile. Each wash involved shaking for 15 min before collecting the peptide extract and pooling with the initial supernatant. Pooled peptide extracts were then lyophilised. Lyophilised peptides were re-suspended in $30 \mu \mathrm{L}$ of $50 \mathrm{mM}$ ammonium bicarbonate per gel section prior to LC-MS/MS analysis with $10 \mu \mathrm{L}$ of each sample injected. Samples were analysed sequentially beginning with the largest molecular weight region on a Thermo Fisher Scientific Orbitrap Velos Pro mass spectrometer coupled to an EASY-nLC II (Thermo Fisher Scientific) nano-liquid chromatography system. Samples were trapped on a $0.1 \times 20 \mathrm{~mm}$ EASY-Column packed with C18-bonded ultrapure silica, $5 \mu \mathrm{m}$ (Thermo Fisher Scientific) and separated on a $0.075 \times 100 \mathrm{~mm}$ EASY-Column packed with C18-bonded ultrapure silica, $3 \mu \mathrm{m}$ (Thermo Fisher Scientific). Columns were equilibrated in $95 \%$ buffer A ( $99.9 \%$ deionised water, $0.1 \%$ formic acid) and $5 \%$ buffer B (99.9 \% acetonitrile, $0.1 \%$ formic acid). Peptides were resolved over $50 \mathrm{~min}$ at a flow rate of $300 \mathrm{~nL} /$ min with a gradient of 5-40\% buffer B for $40 \mathrm{~min}$ followed by a gradient of $40-80 \%$ buffer B for 5 min and held at $80 \%$ buffer $\mathrm{B}$ for a further $5 \mathrm{~min}$. Mass spectra ranging from 400 to $1800 \mathrm{Da}(\mathrm{m} / \mathrm{z})$ were acquired in the Orbitrap at a resolution of 30,000 and the 20 most intense ions were subjected to MS/MS by CID fragmentation in the ion trap selecting a threshold of 5000 counts. The isolation width of precursor selection was 2 units and the normalised collision energy for peptides was 35 . Automatic gain control settings for FTMS survey scans were $10^{6}$ counts and FT MS/MS scans were $10^{4}$ counts. Maximum acquisition time was $500 \mathrm{~ms}$ for survey scans and $250 \mathrm{~ms}$ for MS/MS scans. Charge-unassigned and +1 charged ions were excluded for MS/MS analysis. Raw MS data were processed for database spectral matching using Proteome Discoverer (Thermo Scientific) software. MASCOT was used as the search algorithm with the variable modifications: carbamidomethylation of cysteine and oxidation of methionine. A digestion enzyme of trypsin was set allowing up to three missed cleavages. A parent ion tolerance of $10 \mathrm{ppm}$ and a fragment ion tolerance of $0.5 \mathrm{Da}$ were used.

\section{Bioinformatics}

The peptide sequences for the approximately 5000 toxins deposited in the UniProtKB/Swiss-Prot Tox-Prot dataset (www.uniprot.org/program/Toxins, [59]) were downloaded in FASTA format. Likewise, the predicted proteomes of A. digitifera (http://marinegenomics.oist.jp/genomes/ downloads?project_id=3, [36]) and Symbiodinium clade B1 (http://marinegenomics.oist.jp/genomes/downloads?project_id=21, [60]) were also downloaded in FASTA format and the three datasets were used as query searches for MS/MS spectra. All dataset search results were reviewed by loading the Mascot result files into Scaffold 4 (www.proteomesoftware.com). BLASTp searches were performed to assess local similarities between sequences in the A. digitifera and Symbiodinium clade B1 datasets and the UniProtKB/Swiss-Prot Tox-Prot dataset using program version 2.2.27+ from NCBI (ftp:// ftp.ncbi.nlm.nih.gov/blast,executables/blast+/2.2.27/, [46]). The outputs from these comparisons were parsed and filtered using a custom assembled program written in Python (www.python.org) to select for high scoring segment pairs with e-values selected with a cut-off value below 1.0e ${ }^{-5}$. Sequences of high scoring segment pairs were filtered to remove proteins with likely physiological functions involving Reciprocal Blast Best Hit (RBBH) analysis [61] domain architecture prediction using InterProScan5 (http://www.ebi.ac.uk/Tools/pfa/iprscan5/), a search of gene ontology terms (http://www.ebi.ac.uk/QuickGO/) and prediction of transmembrane domains using TMHMM Server 2.0 (http://www.cbs.dtu.dk/services/ TMHMM/). Grouping of the truncated high scoring segment pairs used our new Hidden Markov Model (HMM) based comparative software designated 'HMMCompare' that is assembled in Python. 'HMMCompare' is freely available at http://bioserv.pbf.hr/HHCompare-master.zip and is implemented using programs from the HHsuite version 2.0 compiled for the Debian based Linux OS (http://wwwuser.gwdg.de/ compbiol/data/hhsuite/releases/ , [47]). Multiple alignments of the truncated sequences were constructed using ClustalW version 2.1 compiled for the Debian based Linux OS (ftp://ftp.ebi.ac.uk/pub/software/ clustalw2/2.1/). Phylogenetic clustering was also performed using Maximum Likelihood and Maximum Parsimony methods in MEGA 6.0 [62] with multiple alignments generated using MUSCLE (http://www.ebi.ac.uk/Tools/msa/muscle/). The clusters were tested for neutral evolution using Tajima's Test of Neutrality [63] implemented in MEGA 6.0.

\section{Additional file}

\footnotetext{
Additional file 1: Clustering and phylogenetic analysis of Acropora digitifera toxins. HMM based hierarchical clustering (HHCompare): HHCompare clustering was performed at HMM-HMM similarity e-value of 1.0e-20. Following the clustering, sequences within each group were aligned using MUSCLE. For three sequence groups, phylogentic trees were constructed using Minimal Evolution method, while larger groups were analyzed using Maximum Likelihood (ML) method. In case of $M L$, evolutionary model was inferred by MEGA 6.0 model selection tool,
} 
based on Sample-corrected Akaike information criterion (AICc). Figure S1. HMM-based hierarchical clustering of coral toxins. Each split indicates HMM-HMM similarity with e-value below 1.0e-20. A: Group 1, ML analysis using $L G+G$ model with 4 discrete gamma categories. B: Group 6, Minimal Evolution analysis. C: Group 9, Minimal Evolution analysis. D Group 10, Minimal Evolution analysis. E: Group 11, ML analysis using JTT model with 4 discrete gamma categories. Figure S2. Phylogenetic analysis of HMM clustered groups. Figure S3. Maximum likelihood based clustering of coral toxins. Sequence names are as following: coral sequence id, followed by evidence for expression ( $T$ stands for True and indicates protein was detected in proteomic analysis of nematocyst, while F stands for False and lack of detection). Last part of sequence name is assigned annotation based on Uniprot ToxProt toxins enriched by Anemone toxins. HMM-clustering generated groups are marked on the tree and groups not generated by HMM clustering, but detected by ML clustering are marked by *. Figure 4 . Maximum parsimony based clustering of coral toxins. (DOCX $61 \mathrm{~kb})$

\section{Competing interests}

The author(s) declare that they have no competing interests.

\section{Authors' contributions}

SRD collected the coral specimens and prepared the nematocysts. RC, AJW and MW carried out the proteomics. RG, DH and AS carried out the bioinformatics analysis. AJB, AC Marques and AC Morandini participated in the data interpretation. PFL conceived the study, and participated in its design and coordination and wrote the manuscript. All authors helped to draft the manuscript and have approved the final version.

\section{Acknowledgments}

We are indebted to Dr. Walter C. Dunlap and Profa. Dra. Ana Maria Moura da Silva for their scientific expertise and guidance during the course of this research; we thank also Prof. Dr. Adalberto Pessoa Júnior and Prof. Dr. Gabriel Padilla for reviewing the manuscript. This work was supported by the United Kingdom Medical Research Council (MRC grant G82144A to R. Gacesa, D. Hranueli and P. F. Long), the Fundação de Amparo à Pesquisa do Estado de São Paulo (FAPESP grants 2010/50174-7 to A. C. Morandini and 2011/50242-5 to A. C. Marques), and by Conselho Nacional de Desenvolvimento Científico e Tecnológico (CNPq grant 301039/2013-5 to A. C. Morandini). Dr P. F. Long is also supported as a Visiting International Research Professor by the Universidade de São Paulo (USP grant 13.1.1502.9.8). This is a contribution to the NP-BioMar program at the Universidade de São Paulo.

\section{Author details}

${ }^{1}$ Institute of Pharmaceutical Science, King's College London, 150 Stamford Street, London SE1 9NH, UK. P2Proteomics Facility, Institute of Psychiatry, Psychology \& Neuroscience, King's College London, 16 De Crespigny Park, London SE5 8AF, UK. ${ }^{3}$ Coral Reefs Ecosystems Laboratory, School of Biological Sciences, The University of Queensland, St. Lucia, QLD 4072, Australia. ${ }^{4}$ Mass Spectrometry Laboratory, UCL School of Pharmacy, 29/39 Brunswick Square, London WC1N 1AX, UK. 5Departamento de Zoologia, Instituto de Biociências, Universidade de São Paulo, Rua Matao, Trav. 14, 101, 05508-090 São Paulo, SP, Brazil. ${ }^{6}$ Centro de Biologia Marinha, Universidade de São Paulo, Rodovia Manoel Hypólito do Rego, km. 131,5, 11600-000 São Sebastião, Brazil. ' Section for Bioinformatics, Department of Biochemical Engineering, Faculty of Food Technology and Biotechnology, University of Zagreb, Pierottijeva 6, 10000 Zagreb, Croatia. ${ }^{8}$ Department of Chemistry, King's College London, Strand, London WC2R 2LS, UK. 'Brazil Institute, King's College London, Strand, London WC2R 2LS, UK. ${ }^{10}$ Faculdade de Ciências Farmacêuticas, Universidade de São Paulo, Av. Prof. Lineu Prestes, 580, B16, 05508-000 São Paulo, SP, Brazil.

\section{Received: 22 July 2015 Accepted: 3 October 2015} Published online: 13 October 2015

\section{References}

1. Fry BG, Roelants K, Champagne DE, Scheib H, Tyndall JD, King GF, et al. The toxicogenomic multiverse: convergent recruitment of proteins into animal venoms. Annu Rev Genomics Hum Genet. 2009;10:483-511.
2. Marques AC, Collins AG. Cladistic analysis of Medusozoa and cnidarians evolution. Invert Biol. 2004;123:23-42.

3. Morandini AC, Marques AC, Custódio MR. Phylum porifera and cnidaria. In: Gopalakrishnakone P, editor. Tonixology - marine and freshwater toxins. Netherlands: Springer Science + Business Media Dordrecht; 2014. p. 1-24.

4. Van Iten H, Marques AC, Leme JM, Pacheco MLAF, Simões MG. Origin and early diversification of the phylum cnidaria verrill: major developments in the analysis of the taxon's proterozoic and earliest Cambrian history. Palaeontol. 2014;4:677-90.

5. Fenner PJ, Harrisson SL. Irukandji and Chironex fleckeri jellyfish envenomation in tropical Australia. Wild Environ Med. 2000;11:233-40.

6. Turk T, Kem WR. The phylum Cnidaria and investigations of its toxins and venoms until 1990. Toxicon. 2009;54:1031-7.

7. Weston AJ, Dunlap WC, Shick JM, Klueter A, Iglic K, Vukelic A, et al. A profile of an endosymbiont-enriched fraction of the coral Stylophora pistillata reveals proteins relevant to microbial-host interactions. Mol Cell Proteomics. 2012;11:M111.015487.

8. Weston AJ, Chung R, Dunlap WC, Morandini AC, Marques AC, Moura-da-Silva $\mathrm{AM}$, et al. Proteomic characterisation of toxins isolated from nematocysts of the South Atlantic jellyfish Olindias sambaquiensis. Toxicon. 2013;71:11-7.

9. Nei M, Gu X, Sitnikova T. Evolution by the birth-and-death process in multigene families of the vertebrate immune system. Proc Natl Acad Sci U S A. 1997:94:7799-806.

10. Kordiš D, Gubenšek F. Adaptive evolution of animal toxin multigene families. Gene. 2000;261:43-52.

11. Casewell NR, Wagstaff SC, Harrison RA, Renjifo C, Wüster W. Domain loss facilitates accelerated evolution and neofunctionalization of duplicate snake venom metalloproteinase toxin genes. Mol Biol Evol. 2011;28:2637-49.

12. Gutiérrez JM, Lomonte B. Phospholipase A2 myotoxins from Bothrops snake venoms. Toxicon. 1995;33:1405-24.

13. Kini RM. Serine proteases affecting blood coagulation and fibrinolysis from snake venoms. Pathophysiol Haemost Thromb. 2005;34:200-4.

14. Le Minh TN, Reza MA, Swarup S, Kini RM. Gene duplication of coagulation factor $V$ and origin of venom prothrombin activator in Pseudonaja textilis snake. Thromb Haemost. 2005;93:420-9.

15. Ogawa T, Chijiwa T, Oda-Ueda N, Ohno M. Molecular diversity and accelerated evolution of C-type lectin-like proteins from snake venom. Toxicon. 2005:45:1-14.

16. Reza MA, Le Minh TN, Swarup S, Kini RM. Molecular evolution caught in action: gene duplication and evolution of molecular isoforms of prothrombin activators in Pseudonaja textilis (brown snake). J Thromb Haemost. 2006;4:1346-53.

17. Fry BG, Wüster W, Kini RM, Brusic V, Khan A, Venkataraman D, et al. Molecular evolution and phylogeny of elapid snake venom three-finger toxins. J Mol Evol. 2003;57:110-29.

18. Zhijian C, Feng L, Yingliang W, Xin M, Wenxin L. Genetic mechanisms of scorpion venom peptide diversification. Toxicon. 2006;47:348-55.

19. Duda Jr TF, Palumbi SR. Molecular genetics of ecological diversification: duplication and rapid evolution of toxin genes of the venomous gastropod Conus. Proc Natl Acad Sci U S A. 1999;96:6820-3.

20. Reyes-Velasco J, Card DC, Andrew AL, Shaney KJ, Adams RH, Schield DR, et al. Expression of venom gene homologs in diverse python tissues suggests a new model for the evolution of snake venom. Mol Biol Evol. 2014;32:173-83.

21. Fry BG. From genome to "venome": Molecular origin and evolution of the snake venom proteome inferred from phylogenetic analysis of toxin sequences and related body proteins. Genome Res. 2005;15:403-20.

22. Vonk FJ, Casewell NR, Henkel CV, Heimberg AM, Jansen HJ, McCleary RJ, et al. The king cobra genome reveals dynamic gene evolution and adaptation in the snake venom system. Proc Natl Acad Sci U S A. 2013;110:20651-6.

23. Casewell NR, Huttley GA, Wüster W. Dynamic evolution of venom proteins in squamate reptiles. Nat Commun. 2012;3:1066.

24. Junqueira-de-Azevedo IL, Val Bastos CM, Ho PL, Luna MS, Yamanouye N, Casewell NR. Venom-related transcripts from Bothrops jararaca tissues provide novel molecular insights into the production and evolution of snake venom. Mol Biol Evol. 2015;32:754-66.

25. Hargreaves AD, Swain MT, Hegarty MJ, Logan DW, Mulley JF. Restriction and recruitment-gene duplication and the origin and evolution of snake venom toxins. Genome Biol Evol. 2014;6:2088-95.

26. Chang D, Duda Jr TF. Extensive and continuous duplication facilitates rapid evolution and diversification of gene families. Mol Biol Evol. 2012;29:2019-29. 
27. Doley R, Mackessy SP, Kini RM. Role of accelerated segment switch in exons to alter targeting (ASSET) in the molecular evolution of snake venom proteins. BMC Evol Biol. 2009;9:146.

28. Lynch M, Conery JS. The evolutionary fate and consequences of duplicate genes. Science. 2000;290:1151-5.

29. Wong ES, Papenfuss AT, Whittington CM, Warren WC, Belov K. A limited role for gene duplications in the evolution of Platypus venom. Mol Biol Evol. 2012;29:167-77.

30. Siigur E, Aaspõllu A, Siigur J. Sequence diversity of Vipera lebetina snake venom gland serine proteinase homologs - result of alternative-splicing or genome alteration. Gene. 2001;263:199-203.

31. Moura-da-Silva AM, Furlan MS, Caporrino MC, Grego KF, Portes-Junior JA, Clissa PB, et al. Diversity of metalloproteinases in Bothrops neuwiedi snake venom transcripts: evidences for recombination between different classes of SVMPs. BMC Genet. 2011;12:94.

32. Sanz L, Harrison RA, Calvete JJ. First draft of the genomic organization of a PIII-SVMP gene. Toxicon. 2012;60:455-69.

33. Dutertre $S$, Jin AH, Kaas $Q$, Jones A, Alewood PF, Lewis RJ. Deep venomics reveals the mechanism for expanded peptide diversity in cone snail venom. Mol Cell Proteomics. 2013;12:312-29.

34. Sullivan JC, Ryan JF, Watson JA, Webb J, Mullikin JC, Rokhsar D, et al StellaBase: the Nematostella vectensis genomics database. Nucleic Acids Res. 2006;34:D495-6.

35. Chapman JA, Kirkness EF, Simakov O, Hampson SE, Mitros T, Weinmaier T, et al. The dynamic genome of Hydra. Nature. 2010;464:592.

36. Shinzato C, Shoguchi E, Kawashima T, Hamada M, Hisata K, Tanaka M, et al. Using the Acropora digitifera genome to understand coral responses to environmental change. Nature. 2011;476:320-3.

37. Balasubramanian PG, Beckmann A, Warnken U, Schnölzer M, Schüler A

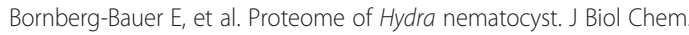
2012;287:9672-81.

38. Dunlap WC, Starcevic A, Baranasic D, Diminic J, Zucko J, Gacesa R, et al. KEGG orthology-based annotation of the predicted proteome of Acropora digitifera: ZoophyteBase - an open access and searchable database of a coral genome. BMC Genomics. 2013;14:509.

39. Van Iten $H$, Leme JM, Marques AC, Simões MG. Alternative interpretations of some earliest Ediacaran fossils from China. Acta Palaeontol Pol. 2013;58:111-3.

40. Starcevic A, Long PF. Diversification of animal venom peptides - were jellyfish amongst the first combinatorial chemists? ChemBioChem. 2013;14:1407-9.

41. Rachamim T, Morgenstern D, Aharonovich D, Brekhman V, Lotan T, Sher D. The dynamically evolving nematocyst content of an anthozoan, a scyphozoan, and a hydrozoan. Mol Biol Evol. 2015;32:740-53.

42. Brinkman DL, Jia X, Potriquet J, Kumar D, Dash D, Kvaskoff D, et al. Transcriptome and venom proteome of the box jellyfish Chironex fleckeri. BMC Genomics. 2015;16:407.

43. Oliveira JS, Fuentes-Silva D, King GF. Development of a rational nomenclature for naming peptide and protein toxins from sea anemones. Toxicon. 2012;60:539-50.

44. Temple-Smith P. Seasonal breeding biology of the platypus, Ornithorhynchus anatinus with special reference to the male, Ph.D. thesis. Canberra: Australian National University; 1973.

45. Casewell NR, Wüster W, Vonk FJ, Harrison RA, Fry BG. Complex cocktails: the evolutionary novelty of venoms. Trends Ecol Evol. 2013;28:219-29.

46. Altschul SF, Gish W, Miller W, Myers EW, Lipman DJ. Basic local alignment search tool. J Mol Biol. 1990;215:403-10.

47. Biegert A, Mayer C, Remmert M, Söding J, Lupas AN. The MPI Bioinformatics Toolkit for protein sequence analysis. Nucleic Acids Res. 2006;34(Web Server issue):W335-9.

48. Binford GJ, Bodner MR, Cordes MHJ, Baldwin KL, Rynerson MR, Burns SN, et al. Molecular evolution, functional variation, and proposed nomenclature of the gene family that includes sphingomyelinase $D$ in sicariid spider venoms. Mol Biol Evol. 2009;26:547-66.

49. Force A, Lynch M, Pickett FB, Amores A, Yan YL, Postlethwait J. Preservation of duplicate genes by complementary, degenerative mutations. Genetics. 1999:151:1531-45.

50. Jouiaei M, Sunagar K, Gross AF, Scheib H, Alewood PF, Moran Y, et al. Evolution of an ancient venom: recognition of a novel family of cnidarian toxins and the common evolutionary origin of sodium and potassium neurotoxins in sea anemone. Mol Biol Evol. 2015. doi:10.1093/molbev/msv050.
51. Frazão B, Vasconcelos V, Antunes A. Sea anemone (Cnidaria, Anthozoa, Actiniaria) toxins: an overview. Mar Drugs. 2012;10:1812-51.

52. Radwan FF, Aboul-Dahab HM. Milleporin-1, a new phospholipase A2 active protein from the fire coral millepora platyphylla nematocysts. Comp Biochem Physiol C Toxicol Pharmacol. 2004;139:267-72.

53. Muscatine $L$. The role of symbiotic algae in carbon and energy flux in reef corals. In: Dubinsky Z, editor. Ecosystems of the World: Coral Reefs. Amsterdam: Elsevier; 1990. p. 75-84.

54. Stanley Jr GD. Photosymbiosis and the evolution of modern coral reefs. Science. 2006;312:857-8.

55. Hutchings PA. Biological destruction of coral reefs. Coral Reefs. 1986;4:239-52.

56. Zundelevich A, Lazar B, Ilan M. Chemical versus mechanical bioerosion of coral reefs by boring sponges - lessons from Pione cf. vastifica. J Exp Biol. 2007;210:91-6

57. Carballo JL, Bautista E, Nava H, Cruz-Barraza A, Chávez JA. Boring sponges, an increasing threat for coral reefs affected by bleaching events. Ecol Evol. 2013;3:872-86.

58. Glasser E, Rachamim T, Aharonovich D, Sher D. Hydra actinoporin-like toxin-1, an unusual hemolysin from the nematocyst venom of Hydra magnipapillata which belongs to an extended gene family. Toxicon. 2014;91:103-13.

59. Jungo F, Bougueleret $L$, Xenarios I, Poux S. The UniProtKB/Swiss-Prot Tox-Prot program: a central hub of integrated venom protein data. Toxicon. 2012;60:551-7.

60. Shoguchi E, Shinzato C, Kawashima T, Gyoja F, Mungpakdee S, Koyanagi R, et al. Draft assembly of the Symbiodinium minutum nuclear genome reveals dinoflagellate gene structure. Curr Biol. 2013;23:1399-408.

61. Altenhoff AM, Dessimoz C. Phylogenetic and functional assessment of orthologs inference projects and methods. PLoS Comput Biol. 2009;5, e1000262.

62. Tamura K, Stecher G, Peterson D, Filipski A, Kumar S. MEGA6: Molecular evolutionary genetics analysis version 6.0. Mol Biol Evol. 2013;30:2725-9.

63. Tajima F. Statistical methods to test for nucleotide mutation hypothesis by DNA polymorphism. Genetics. 1989;123:585-95.

\section{Submit your next manuscript to BioMed Central and take full advantage of:}

- Convenient online submission

- Thorough peer review

- No space constraints or color figure charges

- Immediate publication on acceptance

- Inclusion in PubMed, CAS, Scopus and Google Scholar

- Research which is freely available for redistribution

Submit your manuscript at www.biomedcentral.com/submit 